\title{
Who Will Steer the Ship?
}

During 1973, the existence of two study groups sponsored by the Council on Library Resources became informally known in the library automation community. By the time of the 1974 ALA Midwinter Meeting, the lack of formal identification of these groups, their goals, and their relation to CLR provoked some spontaneous and possibly faulty responses from the ALA members present. In the March 1974 issue of JOLA, Ms. Ruth Tighe analyzed with perception and accuracy the behavior of information scientists attending that meeting.

However, we feel that further attention should be paid to the precise situation in which we find ourselves. The Council on Library Resources has, for eighteen months, funded a small group with the acronym of CEMBI. Informal communication had it that this group of library automation experts originally was to devise a standardized subset of the MARC monograph format; however, a full year passed without public announcement of this work. Unable to come to an agreement, the group seems to have turned to specific strategies for interchange of machine-readable bibliographic data. These goals are, of course, valid and worthy of pursuit.

CLR also announced at Midwinter the intent to administer a system plan for large-scale serials conversion to create a national serials data base. This project draws upon the considerable efforts of the ad hoc "Toronto" group, which provided a status report of its efforts in the December 1973 issue of JOLA.

In addition, an invitational conference was sponsored in April 1974 by CLR, to discuss national bibliographic control, with a small number of conference attendees and with a total absence of publicity.

There are three major problems inherent in the situation described above, affecting not only the library automation community but libraries as a whole.

First, there is no apparent justification for the air of secrecy which has surrounded CLR's direction of these worthy efforts. Surely it must be abundantly clear to all administrators these days that in order to implement a far-reaching program it is necessary to inform if not consult with the target population. Those librarians who are not associated with CLR do not necessarily have axes to grind or home-grown systems to foist upon the world. They do wish to be kept informed of discussion and developments which may eventually have a direct effect upon their work. While it is perfectly reasonable to foster technical progress in a difficult area of study by forming a closed working group of skilled professionals, there seems to be little gained by avoiding recognition of such a group. 
Second, the approach of these projects has sidestepped all the existing channels of operation and communication which we have been striving for over a decade to create. Should CLR wish a certain task performed, it should be able to contract with the Library of Congress or to fund an existing ALA committee to carry out the work. Under the present circumstances, these established channels are likely to find their deliberations bypassed and superseded by these ad hoc groups.

Third, it seems important when determining issues (ad hoc standards for local input of MARC-like monograph and serials records) which are of longrange concern to many libraries, that it is particularly important not to bias a development effort toward the needs of one type of library. The approach of the large research library, while important, is not the only vantage point from which to perceive the problems of nationwide bibliographic systems.

We recommend that the Council on Library Resources find an alternate method of accomplishing its goals-a method which includes provision for adequate communication and which takes advantage of existing channels. Such a method, for the CEMBI group, might be to declare its deliberations to be a user-group standards proposal for submission to the RTSD/ISAD/ RASD Representation in Machine-Readable Form of Bibliographic Information Committee (MARBI), the appropriate ALA committee. If CLR wishes more intensive review of this or any other proposal from MARBI, it could fund the necessary expenses for more frequent meetings of MARBI. An analogous method would establish the serials project as a funded program, with the desired task goals, within the Library of Congress, the National Serials Data Program, or an appropriate library union serials organization.

CLR has done many good deeds for the library world in its lifetime; it would indeed be unfortunate were it to inadvertently allow the growth of professional confusion and resentment that were evident at the Midwinter Meeting.

Susan K. Martin 